\title{
Electroencephalographic changes associated with non-invasive nociceptive stimulus in minimally anaesthetised dogs
}

\author{
U. Kaka ${ }^{1,2}$, Y.M. Goh ${ }^{3}$, L.W. Chean' ${ }^{1}$, H.C. Chen ${ }^{1}$ \\ ${ }^{1}$ Department of Veterinary Clinical Studies, Faculty of Veterinary Medicine, Universiti Putra Malaysia, \\ 43400 Serdang, Selangor, Malaysia \\ ${ }^{2}$ Faculty of Animal Husbandry and Veterinary Sciences, Sindh Agriculture University Tandojam, \\ Sindh 70060, Pakistan \\ ${ }^{3}$ Department of Veterinary Preclinical Sciences, Faculty of Veterinary Medicine, Universiti Putra Malaysia, \\ 43400 Serdang, Selangor, Malaysia
}

\begin{abstract}
Electroencephalography (EEG) has been reported as an objective, non-invasive and stress free technique for nociceptive studies. Electrical stimuli can be used to evaluate the efficacy of centrally acting agents. Peripheral nerve stimulator can be a good and cheap source of electric stimulus for studies of nociception, and studies evaluating analgesic effect of drugs under EEG. In this study suitability of peripheral nerve stimulator, and milliamperage for nociceptive studies under electroencephalography were evaluated. Six dogs were subjected to electric stimulus of 20, 40, 60 and 80 milliamperes (mAs) before and after tramadol administration at $4 \mathrm{mg} / \mathrm{kg}$ IV. Electroencephalograph was recorded during electric stimulus prior tramadol (pre-tramadol) and during electric stimulus after tramadol (post-tramadol) under minimal anaesthesia. Anaesthesia was induced with propofol and maintained with halothane at a stable concentration between 0.85 and $0.95 \%$. Pre-tramadol median frequency (MF) increased significantly ( $\mathrm{p}<0.05)$ at 40,60 and $80 \mathrm{mAs}$ post-electric stimulus compared to baseline MF. No difference in pre-tramadol MF was observed between 60 and $80 \mathrm{mAs}$. Tramadol produced significant effect by depression of MF at all intensities. The effect was less evident at 80 $\mathrm{mAs}$. The results revealed that tramadol produced evident effect between 20 and $60 \mathrm{mAs}$. Thus, it is concluded that nerve stimulator can be used with the current between 20 and $60 \mathrm{mAs}$ for nociceptive studies.
\end{abstract}

Key words: nerve stimulator, electroencephalography, nociception, median frequency, tramadol 


\section{Introduction}

Electroencephalography is the real time graphical representation of tiny (of the microvolt range) spontaneously generated electrical currents of neurons, from the cerebral cortex through electrodes placed on various positions on the scalp in humans or head in other species (Murrell and Johnson 2006). This is a non-invasive and stress free technique and suitable to measure nociception. Therefore, changes in EEG variables of nociception in anaesthetised animals and pain in conscious animals have received much attention (Kongara et al. 2010, Kongara et al. 2014, Zulkifli et al. 2014). Most commonly reported EEG variables in animals are median frequency, spectral edge frequency $95 \%$ and total power (Haga and Dolvik 2005, Johnson et al. 2005, Gibson et al. 2007, Murrell et al. 2007, Kongara et al. 2013). Median frequency is „the frequency below which $50 \%$ of the total power of the EEG is located”. Spectral Edge frequency $95 \%$ is ,the frequency below which $95 \%$ of the total power of the EEG is located”. And the total power is "the total area under the curve" (Murrell and Johnson 2006).

Electroencephalographic changes to pain and nociception are reported to be similar in awake (Zulkifli et al. 2014) and anaesthetised animals (Kongara et al. 2010). Since it is difficult to record EEG in fully conscious animal therefore, a minimal anaesthesia animal model (Murrell and Johnson 2006) has been used successfully to investigate nociception in various animal studies. Minimal anaesthesia implies that the EEG investigation is carried out in lightly anaesthetised animals simulating nociceptive response in awake animals. When compared to other studies where animals are conscious, the minimal anaesthesia model (MAM) has the advantage of including a negative control group, without compromising the animal welfare. It is a sensitive and objective method of evaluating central responses to painful stimulation (Murrell and Johnson 2006). Minimal anaesthesia model has been used in horses (Murrell et al. 2003, Murrell et al. 2005), sheep (Sylvester et al. 2002, Johnson et al. 2005), red deer (Johnson et al. 2005, Woodbury et al. 2005), pigs (Haga and Ranheim 2005), rats (Murrell et al. 2010) and dogs (Kongara et al. 2010). This model uses the EEG response to noxious stimulation as a tool to investigate analgesia for painful manipulations in applied veterinary research.

Noxious electrical stimuli can be used to evaluate the efficacy of centrally acting agents. Electrical stimuli have the advantage of being quantifiable, reproducible and noninvasive. They also have the ability to induce synchronized afferent signals (Le Bars et al. 2001). They activate all peripheral afferent fibers $(A \beta$,
$\mathrm{A} \delta$ and $\mathrm{C}$ fibers) nonselectively, thus, by pass the transduction mechanism. This mechanism, however, can be advantageous in the studies using drugs administered systematically in evaluating their effects on CNS (Le Bars et al. 2001). This model has been used successfully along with minimal anaesthesia and EEG in dogs (Kongara et al. 2010). In their study Kongara et al. (2010) used the supramaximal electrical stimulus with constant voltage (50 Vat $50 \mathrm{~Hz}$ for $2 \mathrm{~s}$ ), using a Grass Stimulator (S48K square pulse stimulator, Astro-Med Inc., Grass instrument division, Auckland, New Zealand).

The grass stimulator is intended for research only and is difficult to be available at every anaesthesiology section, where such type of research is not a routine. On the other hand, the peripheral nerve stimulator is cheaper and available at every anaesthesiolgy unit. This is commonly used to monitor the degree of paralysis after administration of neuromuscular blocking agents to avoid excessive doses. This stimulator is powered by $3 \times 1.5$ volt ,AA" batteries and is very light in weight $(0.18 \mathrm{~kg})$ compared to the grass stimulator $(6.4 \mathrm{~kg})$ which is $\mathrm{AC}$ powered. The peripheral nerve stimulator N272 (Fisher and Paykel Healthcare international, New Zealand) is cheaper than Grass Stimulator (S48K square pulse stimulator). Therefore, it can serve as good economic alternate of grass stimulator for the studies of nociception using EEG. Thus, the aim of this study was to evaluate the suitability of the peripheral nerve stimulator and to identify the milliamperage required to evoke nociceptive EEG response. Furthermore, this study aimed to determine the threshold which can evoke changes in various EEG parameters, useful for the nociceptive studies in a dog model.

\section{Materials and Methods}

\section{Animals}

Six adult dogs weighing between $15-17 \mathrm{~kg}$ body weight, comprising 5 males and 1 female were used in this study. The animals were obtained from Pusat Kurungan Haiwan, Jabatan Kesihatan DBKL, off Jalan Air Jerneh, Kampung Air Kunning, Air Panas, Setapak, 53300, Kuala Lumpur. These dogs were then kept under observation for any disease or abnormality for one week. Unhealthy animals were excluded based on clinical signs. Finally, the dogs were judged healthy based on physical examination, hematology, and blood biochemistry. The animals were housed in kennels, one animal per kennel with dimension of 2.6' $x$ 5.6' with clean cement floor. They were fed commercial dog feed twice daily with water ad libitum. 


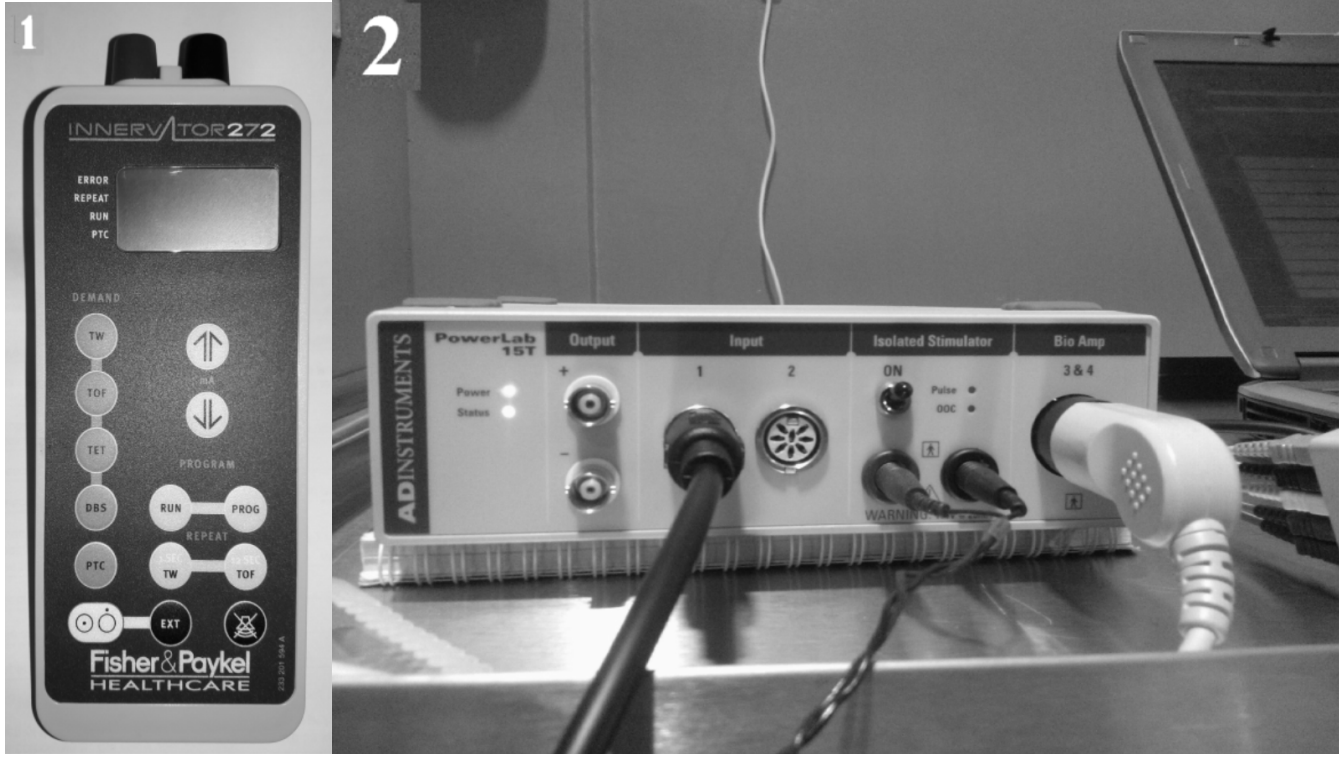

Fig. 1. Peripheral nerve stimulator N272; fig. 2. Powerlab data recording system (Powerlab data acquisition system, AD Instruments Ltd. Sydney, Australia).

Kennels were cleaned on daily basis with antiseptic solution. The dogs were routinely taken out for a walk and exercise daily in evening for half an hour. The study was subjected to the review and approved by the Universiti Putra Malaysia Animal Care and Use Committee (UPM/IACUC/AUP-R023/ 2013).

\section{Anaesthesia protocol}

The dogs were fasted for 12 hours before anaesthesia with free access to water. Left forelimbs of the animals were shaved with clipper and aseptically catheterized with 20 gauge catheter (Vasofix ${ }^{\circledR}$ Braunule $^{\circledR}$, B. Braune Melsungen AG 34209 Melsungen, Germany) placed in the cephalic vein. Anaesthesia was induced by administration of propofol $(5 \mathrm{mg} / \mathrm{kg} \mathrm{IV}$, Profol $^{\mathrm{TM}} 1 \%$, Claris Life sciences Limited, India) over 1 minute and maintained with halothane. The halothane concentration was maintained using Surgivet halothane vaporizer machine at end-tidal halothane concentration (ETHAL) between $0.85 \%$ and $0.95 \%$ as per levels recommended by Kongara et al. (2010). All the animals breathed spontaneously and were positioned on right lateral recumbency. Lactated Ringer's solution was administered to maintain mean blood pressure above $60 \mathrm{mmHg}$ throughout the anaesthetic period. A blood pressure cuff with $40-60 \%$ width of the circumference of the antebrachium was used to measure blood pressure. All parameters were monitored using Datex-Ohmeda monitor (GE healthcare, Finland Oy, Helsinki, Finland). Temperature was maintained between 37 and $38^{\circ} \mathrm{C}$ using a heating pad and warm blanket.

\section{Operational mechanism of $\mathbf{N} 272$ peripheral nerve stimulator}

The peripheral nerve stimulator N272 automatically adjusts the output voltage to deliver a constant current with maximum output of 80 milliamperes (mAs). It works in internal mode (0.2 to $10 \mathrm{mAs}$ ) and external mode (10 to $80 \mathrm{mAs}$ ). It can deliver current in single pulse (TW), train of four with each pulse of $0.5 \mathrm{sec}$ duration (TF), tetanus pulse train of 5 seconds duration (TET), double burst pulse train with 3 pulses of 20 milliseconds (ms), a $750 \mathrm{~ms}$, then 2 or $3,20 \mathrm{~ms}$ pulses (DBS), post tetanic count with 5 seconds tetanus pulse, with 3 seconds pause and 20 twitch pulses at $1 \mathrm{~Hz}$ (PTS). All these functions are in external mode excluding single pulse (TW) (Fig. 1).

\section{Experimental Procedure}

\section{Electroencephalography}

The electroencephalogram was recorded using a personal computer installed with Chart 5.5.5 recording software and connected to Powerlab 4/20 data recording system (Powerlab data acquisition system, AD Instruments Ltd. Sydney, Australia) (Fig. 2). Three stainless steel sterile disposable acupuncture needles (Wuxi Jiajian Medical Instrument Co., Ltd. Wuxi, Jiangsu, China) were placed subcutaneously, with the inverting electrode (-ve) over the zygomatic process of the left frontal bone, the non-inverting electrode (+ve) over the left mastoid process, and the ground electrode caudal to the occipital process (Murrell and 


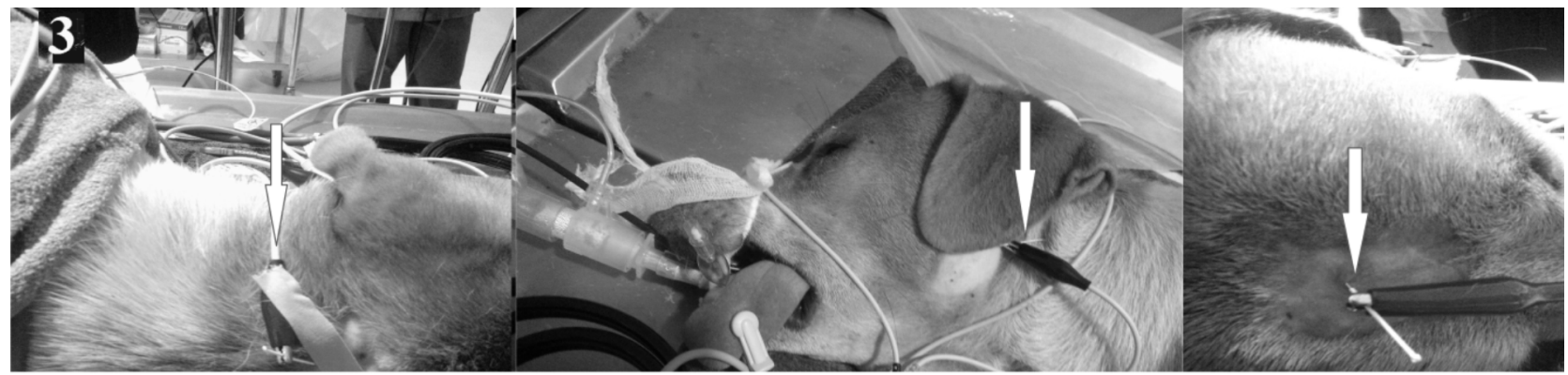

Fig. 3. Position of the electrodes (arrows) on an anaesthetised dog for EEG recording.

Johnson 2006) (Fig. 3). Care was taken to ensure that the total impedance of the circuitry was less than $5 \mathrm{kOhms}$.

The electroencephalogram was recorded at a sampling rate of $1 \mathrm{kHz}$ and raw EEG was resampled with low pass filter of $200 \mathrm{~Hz}$ into delta frequency $(0.1$ to $4 \mathrm{~Hz}$ ), theta frequency $(4.1$ to $8 \mathrm{~Hz})$, alpha frequency ( 8.1 to $12 \mathrm{~Hz}$ ), and beta frequency (12.1 to 20 $\mathrm{Hz}$ ) as reported earlier (Zulkifli et al. 2014). Electroencephalographic data were recorded during electric stimulus prior (pre-tramadol) and after tramadol (post-tramadol) under minimal anaesthesia. Electrocardiogram was recorded continuously in the standard lead II configuration, with the negative electrode on the right forelimb and positive electrode on the left hind limb.

Analysis of the EEG data was performed offline after the completion of the experiments. The overall median frequency (MF), total EEG power (Ptot) and root means square (RMS) values for alpha, beta, delta and theta waves were calculated for consecutive non overlapping 1-second epochs. Power density data were derived using a Cosine-Bell function. Electrical and mechanical interference were excluded from EEG data during stimulus application by excluding wave signals five to seven seconds before and after the nociceptive electrical stimulus. EEG data from 10-second blocks prior to and 10-second blocks following electrical stimulus were taken for statistical analysis (Zulkifli et al. 2014).

\section{Electric stimulus}

Following induction, the dogs were maintained on halothane for 90 minutes to allow instrumentation and minimise residual effect of propofol. Baseline EEG data were recorded for 10 minutes, before (T0b) and after (T0a) electric stimulation. Noxious stimuli were given in a random order (Table 1) before and after administration of tramadol (4 mg/kg IV) (Fig. 4) (Giorgi et al. 2010) at 20, 40, 60 and $80 \mathrm{mAs}$ and 50 $\mathrm{Hz}$ with a peripheral nerve stimulator N272 (Fisher and Paykel Healthcare International, New Zealand) for 5 seconds, at tetanus pulse train function (TET). As per user manual, the device can provide maximum output voltage of $350 \pm 10 \% \mathrm{~V}$ in external mode, which was the mode employed for this study. The stimulus was applied to the left hind limb (lateral aspect of the distal metatarsus) through two subdermal needle electrodes placed subcutaneously $2 \mathrm{~cm}$ apart (Kongara et al. 2010) (Fig. 5). At the end of each experiment, halothane was disconnected and the dogs were extubated when the laryngeal reflexes returned.

\section{Statistical Analysis}

The data are presented as median values. Prior to analysis, the data were checked for their conformance to the normal distribution using the Kolmogrov-Smirnov normality test. The data were found to be not normally distributed, and therefore, the Friedman test was used to determine the changes in median frequencies (MF) and total power (Ptot) of the EEG, as a response to noxious stimulus, before and after tramadol administration. Significant means were differentiated using non parametric comparison test. All analysis was conducted at $95 \%$ confidence level using IBM SPSS software version 21 (SPSS Inc., Chicago, USA).

\section{Results}

\section{Median frequency}

Median frequency increased significantly with increasing magnitude of milliamperage (mAs) from 20 to $80 \mathrm{mAs}$. This increment was significant at $40 \mathrm{mAs}$ $(\mathrm{p}=.028), 60 \mathrm{mAs}(\mathrm{p}=.046)$ and $80 \mathrm{mAs}(\mathrm{p}=0.028)$ except at $20 \mathrm{mAs}(\mathrm{p}=0.345)$. Increase in the median frequency coincided with increase in the $\mathrm{mAs}$ (Table 1). Maximum increase in MF was observed at 60 and $80 \mathrm{mAs}$, which was not significant from each other $(p=0.345)$. Tramadol depressed the increase 
Table 1. Sequence of the treatment.

\begin{tabular}{|c|c|c|c|c|c|c|c|c|c|}
\hline \multicolumn{10}{|c|}{ Treatment sequence } \\
\hline \multicolumn{5}{|c|}{ PRESTIMULATION } & $\mathbf{T}$ & \multicolumn{4}{|c|}{ POST STIMULATION } \\
\hline Animal & & & & & $\mathbf{R}$ & & & & \\
\hline 1 & 20 & 40 & 60 & 80 & $\mathbf{A}$ & 20 & 40 & 60 & 80 \\
\hline 2 & 40 & 60 & 80 & 20 & $\mathbf{M}$ & 40 & 60 & 80 & 20 \\
\hline 3 & 60 & 80 & 20 & 40 & $\mathbf{A}$ & 60 & 80 & 20 & 40 \\
\hline 4 & 80 & 20 & 40 & 60 & D & 80 & 20 & 40 & 60 \\
\hline 5 & 20 & 60 & 40 & 80 & $\mathbf{O}$ & 20 & 60 & 40 & 80 \\
\hline 6 & 40 & 80 & 60 & 20 & $\mathbf{L}$ & 40 & 80 & 60 & 20 \\
\hline
\end{tabular}

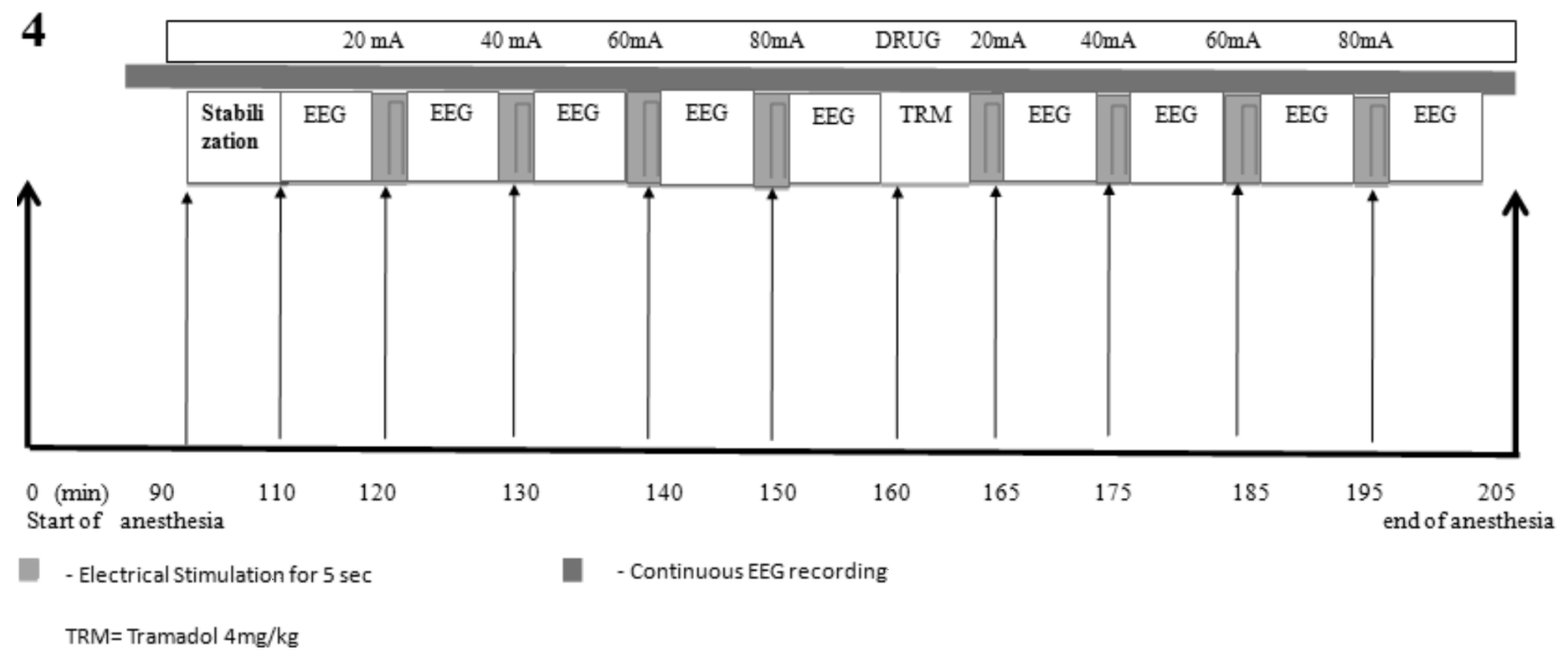

Fig. 4. Time line of the experiment.

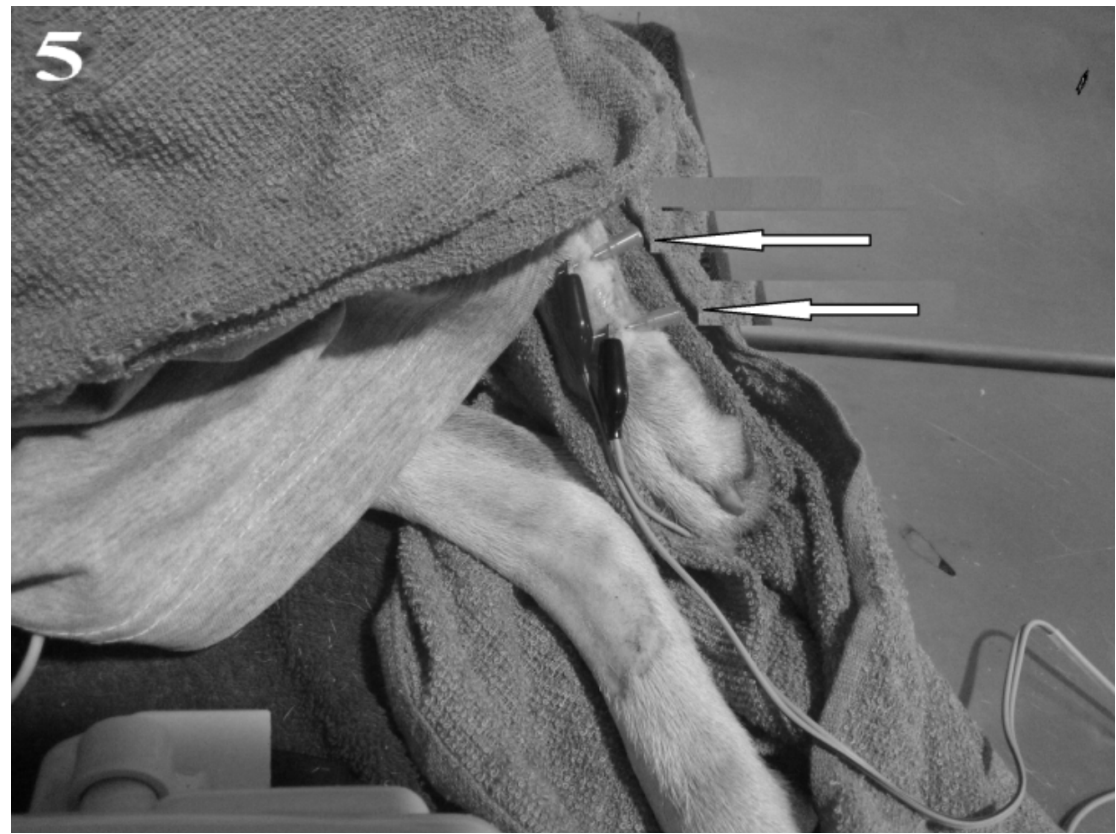

Fig. 5. Position of electrodes (arrows) for electrical stimulus. 
Table 2. Pre-and post-treatment median values (range) of MF ( $\mathrm{Hz})$ values.

\begin{tabular}{|c|c|c|c|c|c|}
\hline & Baseline & $20 \mathrm{mAs}$ & $40 \mathrm{mAs}$ & $60 \mathrm{mAs}$ & $80 \mathrm{mAs}$ \\
\hline Pre-tramadol & $7.86(4.88-9.37)^{\mathrm{a}, \mathrm{x}}$ & $10.40(3.81-17.38)^{\mathrm{ab}, \mathrm{x}}$ & $13.76(11.82-15.53)^{\mathrm{bc}, \mathrm{x}}$ & $17.43(7.42-23.00)^{\mathrm{c}, \mathrm{x}}$ & $17.03(11.42-43.77)^{\mathrm{c}, \mathrm{x}}$ \\
\hline Post-tramadol & $6.54(5.37-10.16)^{\mathrm{a}, \mathrm{x}}$ & $10.05(5.27-19.53)^{\mathrm{a}, \mathrm{x}}$ & $10.05(5.27-13.67)^{\mathrm{a}, \mathrm{y}}$ & $9.37(2.93-19.53)^{\mathrm{a}, \mathrm{y}}$ & $12.54(4.20-37.68)^{\mathrm{a}, \mathrm{x}}$ \\
\hline
\end{tabular}

Table 3. Pre-and post-treatment median values (range) of Ptot $\left(\mu V^{2}\right)$ values.

\begin{tabular}{cccccc}
\hline & Pre-stimulation & $20 \mathrm{mAs}$ & $40 \mathrm{mAs}$ & $60 \mathrm{mAs}$ & $80 \mathrm{mAs}$ \\
\hline Pre-tramadol & $8.45(6.10-10.07)^{\mathrm{a}, \mathrm{x}}$ & $8.44(4.50-23.22)^{\mathrm{a}, \mathrm{x}}$ & $6.92(5.22-12.33)^{\mathrm{a}, \mathrm{x}}$ & $9.53(6.11-15.37)^{\mathrm{a}, \mathrm{x}}$ & $7.25(6.19-13.74)^{\mathrm{a}, \mathrm{x}}$ \\
\hline Post-tramadol & $7.68(6.50-10.03)^{\mathrm{a}, \mathrm{x}}$ & $6.86(4.90-13.02)^{\mathrm{a}, \mathrm{x}}$ & $6.89(6.25-10.99)^{\mathrm{a}, \mathrm{x}}$ & $6.42(5.99-15.72)^{\mathrm{a}, \mathrm{x}}$ & $8.18(6.10-17.07)^{\mathrm{a}, \mathrm{x}}$ \\
\hline
\end{tabular}

$\mathrm{a,b}$, means within rows with different letters differ at $\mathrm{p}<0.05$.

$\mathrm{x}, \mathrm{y}$, means within columns with different letters differ at $\mathrm{p}<0.05$.

Ptot $=$ total power

Table 4. Pre-and post-treatment median values (range) of Alpha wave RMS $(\mu \mathrm{V})$ values.

\begin{tabular}{cccccc}
\hline & Baseline & $20 \mathrm{mAs}$ & $40 \mathrm{mAs}$ & $60 \mathrm{mAs}$ & $80 \mathrm{mAs}$ \\
\hline Pre-tramadol & $2.43(1.83-2.57)^{\mathrm{a}, \mathrm{x}}$ & $1.48(1.21-2.60)^{\mathrm{b}, \mathrm{x}}$ & $1.25(1.09-1.96)^{\mathrm{b}, \mathrm{x}}$ & $1.34(1.00-2.04)^{\mathrm{b}, \mathrm{x}}$ & $1.29(.96-2.32)^{\mathrm{b}, \mathrm{x}}$ \\
\hline Post-tramadol & $1.56(1.44-2.51)^{\mathrm{a}, \mathrm{x}}$ & $1.20(1.09-1.63)^{\mathrm{b}, \mathrm{x}}$ & $1.17(.96-1.59)^{\mathrm{a}, \mathrm{x}}$ & $1.29(.90-1.59)^{\mathrm{b}, \mathrm{x}}$ & $1.13(1.01-1.60)^{\mathrm{a}, \mathrm{x}}$ \\
\hline
\end{tabular}

abc, means within rows with different letters differ at $\mathrm{p}<0.05$.

${ }^{\mathrm{xy}}$, means within columns with different letters differ at $\mathrm{p}<0.05$.

Table 5. Pre-and post-treatment median values (range) of Beta wave RMS $(\mu \mathrm{V})$ values.

\begin{tabular}{cccccc}
\hline & Baseline & $20 \mathrm{mAs}$ & $40 \mathrm{mAs}$ & $60 \mathrm{mAs}$ & $80 \mathrm{mAs}$ \\
\hline Pre-tramadol & $2.72(2.51-3.94)$ & $2.67(1.97-3.10)$ & $2.04(1.82-3.13)$ & $2.72(1.65-4.35)$ & $2.37(2.11-2.89)$ \\
\hline Post-tramadol & $2.01(1.70-3.16)$ & $2.23(1.54-2.45)$ & $2.07(1.90-3.30)$ & $2.13(1.77-2.17)$ & $1.97(1.62-2.52)$ \\
\hline
\end{tabular}

No significant difference between the values

Table 6. Pre-and post-treatment median values (range) of Delta wave RMS $(\mu \mathrm{V})$ values.

\begin{tabular}{cccccc}
\hline & Baseline & $20 \mathrm{mAs}$ & $40 \mathrm{mAs}$ & $60 \mathrm{mAs}$ & $80 \mathrm{mAs}$ \\
\hline Pre-tramadol & $4.35(3.27-6.01)$ & $3.90(1.93-13.11)$ & $2.31(1.49-5.96)$ & $2.90(1.76-8.37)$ & $2.30(2.17-2.45)$ \\
\hline Post-tramadol & $3.62(3.21-5.55)$ & $3.21(2.10-9.91)$ & $3.67(2.17-7.28)$ & $3.05(2.97-8.58)$ & $3.71(1.92-6.66)$ \\
\hline
\end{tabular}

No significant difference between the values

Table 7. Pre-and post-treatment median values (range) of Theta wave RMS $(\mu \mathrm{V})$ values.

\begin{tabular}{lccccc}
\hline \multicolumn{2}{c}{ Baseline } & $20 \mathrm{mAs}$ & $40 \mathrm{mAs}$ & $60 \mathrm{mAs}$ & $80 \mathrm{mAs}$ \\
\hline Pre-tramadol & $2.94(2.50-3.50)^{\mathrm{a}, \mathrm{x}}$ & $2.06(1.44-2.53)^{\mathrm{b}, \mathrm{x}}$ & $1.27(1.11-1.83)^{\mathrm{b}, \mathrm{x}}$ & $1.22(1.03-2.37)^{\mathrm{b}, \mathrm{x}}$ & $1.23(1.05-2.47)^{\mathrm{b}, \mathrm{x}}$ \\
\hline Post-tramadol & $2.83(1.62-3.59)^{\mathrm{a}, \mathrm{x}}$ & $1.79(1.11-3.27)^{\mathrm{b}, \mathrm{x}}$ & $1.77(1.07-2.62)^{\mathrm{b}, \mathrm{x}}$ & $1.70(1.25-3.19)^{\mathrm{b}, \mathrm{x}}$ & $1.41(1.29-2.27)^{\mathrm{b}, \mathrm{x}}$ \\
\hline abc means within rows with different letters differ at $\mathrm{p}<0.05$. \\
xy means within columns with different letters differ at $\mathrm{p}<0.05$. \\
$\mathrm{MF}=$ median frequency
\end{tabular}


in the median frequency at all intensities of electric stimulation. This depression was less at $80 \mathrm{mAs}$, which was not different from MF at similar intensity of electric stimulus in pre-tramadol stimulation $(\mathrm{p}=0.075)$. Post-tramadol depression of MF was significantly higher at 40 and $60 \mathrm{mAs}$, at which point the post-tramadol MF were significantly lower from pre-tramdol stimulation at $40 \mathrm{mAs}(\mathrm{p}=0.046)$ and at $60 \mathrm{mAs}(\mathrm{p}=0.028)$. There was no difference between pre- and post-tramadol baseline MF $(\mathrm{p}=0.600)$ (Table 2).

\section{Total power of EEG}

There was no significant difference in the Ptot before and after tramadol with increasing strength of electric stimulus (Table 3).

\section{Root Mean Square (RMS) of alpha, beta, delta and theta bands}

There was no significant difference between baseline RMS of alpha, beta, delta and theta waves of the EEG before and after tramadol (Tables 4-7). The RMS of alpha wave decreased significantly $(p=0.010)$ after noxious electric stimulus, pre and post-tramadol administration. Similar trend was observed in the RMS of theta wave $(p=0.001)$ after noxious electric stimulus, pre- and post-tramadol administration. Whereas, beta wave $(p=0.187)$ and delta wave $(p=0.437)$ activities did not show any significant change in RMS with increasing strength of stimuli, pre- and post-tramadol treatment $(\mathrm{p}>0.05)$.

\section{Discussion}

The present results showed that there was a significant increase in median frequency after electrical stimuli, but prior to tramadol administration among the experimental subjects. This is a typical EEG response consistent with nociceptive response observed in many species of animals, such as rats, horses, lambs, calves, deer and dogs (Otto et al. 1996, Murrell et al. 2003, Johnson et al. 2005a,b, Gibson et al. 2007, Murrell et al. 2007, Kongara et al. 2010). Similar findings have also been reported in human patients with increasing strength of the stimuli as long as the magnitude of stimulus is kept below the critical supramaximal threshold (Harper et al. 2001). A current of 50 to $60 \mathrm{mAs}$ has been reported to be supramaximal in all patients during anaesthesia (Kopman and Lawson 1984). In a human study, median supramaximal cur- rent was $40 \mathrm{mAs}$ in non-oedematous limbs compared to $60 \mathrm{mAs}$ in Grade 1 edema and $82.5 \mathrm{mAs}$ in Grade 2 edema (Harper et al. 2001). The present results concur with findings in human studies and affirm that current between 40 and $60 \mathrm{mAs}$ can be used for the noxious electric stimulus.

Tramadol administration significantly depressed the MF at all intensities of electric stimuli compared to pre- and post-tramadol baseline MF values. The maximum effect was detected at electric stimulus of 40 and $60 \mathrm{mAs}$. The effect of tramadol was less pronounced at $80 \mathrm{mAs}$, at which point the pre- and post-tramadol MF values were not different from each other. Indeed, it was observed that stimuli equivalent or higher than $60 \mathrm{mAs}$ in this study resulted in cascading increases in median frequencies. This further suggests that $60 \mathrm{mAs}$ could be the supramaximal threshold stimulus beyond which tramadol may have less effect on the inhibition of transmission of a response to the brain.

In the present study, tramadol had less effect on electric stimulus beyond $60 \mathrm{mAs}$. The primary role of a $\mu$-opioid agonist is to prevent pre-synaptic release of neurotransmitter and hyperpolarisation of post-synaptic membrane, thereby decreasing transmission of afferent nociceptive signals (Duggan and North 1984). Tramadol has weak affinity for the $\mu, \delta$, and $\kappa$ opioids receptors (KuKanich and Papich 2004, McMillan et al. 2008). It is therefore postulated that weak $\mu$-opioid receptor affinity to tramadol may be partially responsible in allowing residual afferent transmission to the cerebral cortex after noxious stimulation beyond 60 mAs. The results of this study are different from those of the previous study conducted by Kongara et al. (2010) in dogs (Kongara et al. 2010). Tramadol did not depress the increase in MF after electric stimulation compared to morphine. In this study, tramadol was administered at $4 \mathrm{mg} / \mathrm{kg}$ IV and the data were taken between 10 to 40 minutes after injection of tramadol. Kongara used tramadol at $3 \mathrm{mg} / \mathrm{kg} \mathrm{SC}$ and the time of data collection was 2.5 hours after the administration. Pharmacokinetics, dose and time of data collection might be the reason why tramadol could not depress the MF in previous study by Kongara et al. (2010). The reason for the difference in the results of this study and Kongara's study might be the dose used and time of the data collection.

Tramadol has been reported to have least sedative effects compared to other opioids (Monteiro et al. 2009). No significant difference between preand post-tramadol baseline MF suggests that tramadol had no significant depressive effect on the CNS in this study. Thus, the results of this study further affirm the results of the previous study by Monteiro et al. (2009). 
There was no post-stimulation change observed in Ptot, either before or after tramadol administration at any of the electric current intensity used in this study. The relationship between $\mathrm{ET}_{\mathrm{HAL}}$ and Ptot in response to surgical castration in horses has been reported by Murrell et al. (2003). Total power was reduced significantly in response to castration in horses. It was suggested that the decrease in the Ptot indicates reduction in the adequacy of anaesthesia due to noxious stimuli. In a study conducted on dogs, Ptot decreased significantly after electric stimulation followed by administration of morphine (Kongara et al. 2010). On the contrary, Ptot did not decrease from baseline in response to castration after administration of morphine (Kongara et al. 2013); whereas, tramadol was unable to prevent decrease in Ptot at the time of testicle removal in the same study. This discrepancy in the results reported and results of this study may likely be due to the difference in the experimental conditions or intensity of noxious stimulations used. These lines of evidence suggested that ptot may not be good indicator of nociception, unlike the MF.

The RMS values for alpha and theta waves decreased significantly after electric stimulation pre- and post-tramadol administration. On the other hand, RMS values for beta and delta waves did not show any significant change. There is a paucity of literature regarding the change in RMS values of the alpha, beta, delta and theta waves in response to noxious stimuli in animals. However, in one study conducted in goats, alpha, delta and theta power decreased in response to mechanical noxious stimulus (Antognini et al. 2000). On the contrary, total power in all alpha, beta, delta and theta waves increased after stimulation in sheep (Ong et al. 1997). Whereas, the RMS values for alpha and beta increased in response to noxious stimulus in cattle (Zulkifli et al. 2014). The alpha waves are known to dominate when subjects closed their eyes (Toscani et al. 2010). In a conscious subject, eye closure will lead to a simultaneous decrease in beta wave intensities in the absence of any stimuli. Among the minimally anesthetized dogs, it is apparent that only alpha and theta waves were depressed following electrical stimuli. This could be partly due to the fact that magnitude of the noxious electrical stimulus used in this experiment, was far lesser than the ones reported earlier by Zulkifli et al. (2014) and Antognini et al. (2000). Conversely, stimulus was of high magnitude in this experiment compared to that reported by Ong et al. (1997) where sheep were conscious. Beta waves are typically suppressed in anesthetized animals (Schwender et al. 1998), and increased in the presence of stress and other stimuli (Trucchi et al. 2003, Zulkifli et al. 2014). Cattles were conscious and subjected to neck cut incision (Zulkifli et al. 2014) and goats were under isoflurane anesthesia, subjected to mechanical stimulus (Antognini et al. 2000). It should be noted that RMS changes may also vary across species and age groups (Ong et al. 1997, Antognini et al. 2000, Trucchi et al. 2003, Johnson et al. 2005, Zulkifli et al. 2014). The present study also demonstrated that the RMS of various wave bands explored has limited utility in understanding nociception and its relief in the dog MAM model, at the very least. In summary, these further underscored the need to identify a minimum stimulus threshold, in order to accurately study the effects of analgesics in the dog model. In this case, it has been shown that MF change is a more important parameter to consider when monitoring for drug effects and noxious stimuli responses in the dog MAM model.

\section{Conclusion}

In conclusion, activities of EEG corroborated well with the evidence of analgesia among the experimental animals. Median frequency is a reliable indicator of EEG analgesia. The present study also showed that tramadol provided evident analgesia for non-invasive stimulus between 20 and $60 \mathrm{mAs}$. It is recommended that the peripheral nerve stimulator with the current between 20 and $60 \mathrm{mAs}$ can be used as source of electric stimulation for the nociceptive studies using electroencephalography.

\section{Authors' contribution}

UK, YMG and CHC contributed to the original idea and design of the study. LWC and UK conducted the experiments and collected the data. UK, YMG and LWC performed statistical analysis. All the authors were involved in the manuscript preparation and approved the final version.

\section{References}

Antognini JF, Wang XW, Carstens E (2000) Isoflurane action in the spinal cord blunts electroencephalographic and thalamic-reticular formation responses to noxious stimulation in goats. Anesthesiology 92: 559-566.

Duggan AW, North RA (1984) Electrophysiology of opioids. Pharmacol Rev 35: 219-181.

Gibson TJ, Johnson CB, Stafford KJ, Mitchinson SL, Mellor DJ (2007) Validation of the acute electroencephalographic responses of calves to noxious stimulus with scoop dehorning. N Z Vet J 55: 152-157.

Giorgi M, Del Carlo S, Łebkowska-Wieruszewska B, Kowalski CJ, Saccomanni G (2010) Pharmacokinetics of tramadol and metabolites after injective administrations in dogs. Pol J Vet Sci 13: 639-644. 
Haga HA, Dolvik NI (2005) Electroencephalographic and cardiovascular variables as nociceptive indicators in isoflurane-anaesthetized horses. Vet Anaesth Analg 32: 128-135.

Haga HA, Ranheim B (2005) Castration of piglets: the analgesic effects of intratesticular and intrafunicular lidocaine injection. Vet Anaesth Analg 32: 1-9.

Harper NJ, Greer R, Conway D (2001) Neuromuscular monitoring in intensive care patients: milliamperage requirements for supramaximal stimulation. Bri J Anaesth 87: 625-627.

Johnson CB, Wilson PR, Woodbury, MR, Caulkett NA (2005) Comparison of analgesic techniques for antler removal in halothane anaesthetized red deer (Cervus elaphus): electroencephalographic responses. Vet Anaesth Analg 32: 61-71.

Johnson CB, Stafford KJ, Sylvester SP, Ward R, Mitchinson, $\mathrm{S}$, Mellor, DJ (2005) Effects of age on the electroencephalographic response to castration in lambs anaesthetised using halothane in oxygen. N Z Vet J 53: 433-437.

Kongara K, Chambers JP, Johnson, CB (2010) Electroencephalographic responses of tramadol, parecoxib and morphine to acute noxious electrical stimulation in anaesthetised dogs. Res Vet Sci 88: 127-133.

Kongara K, Chambers JP, Johnson CB, Dukkipati VS (2013) Effects of tramadol or morphine in dogs undergoing castration on intra-operative electroencephalogram responses and post-operative pain. N Z Vet J 61: 349-353.

Kongara K, McIlhone AE, Kells NJ, Johnson CB (2014) Electroencephalographic evaluation of decapitation of the anaesthetized rat. Lab Anim 48: 15-19.

Kopman AF, Lawson D (1984) Milliamperage requirements for supramaximal stimulation of the ulnar nerve with surface electrodes. Anesthesiology 61: 83-85.

KuKanich B, Papich MG (2004) Pharmacokinetics of tramadol and the metabolite O-desmethyltramadol in dogs. J Vet Pharmacol Ther 27: 239-246.

Le Bars D, Gozariu M, Cadden SW (2001) Animal models of nociception. Pharmacol Rev 53: 597-652.

McMillan CJ, Livingston A, Clark CR, Dowling PM, Taylor SM, Duke T, Terlinden R (2008) Pharmacokinetics of intravenous tramadol in dogs. Can J Vet Res 72: 325-331.

Monteiro ER, Junior AR, Assis HM, Campagnol D, Quitzan JG (2009) Comparative study on the sedative effects of morphine, methadone, butorphanol or tramadol, in combination with acepromazine, in dogs. Vet Anaesth Analg 36: 25-33.

Murrell JC, Johnson CB (2006) Neurophysiological techniques to assess pain in animals. $\mathrm{J}$ Vet Pharmacol Ther 29: 325-335.
Murrell JC, Johnson CB, White KL, Taylor PM, Haberham ZL, Waterman-Pearson AE (2003) Changes in the EEG during castration in horses and ponies anaesthetized with halothane. Vet Anaesth Analg 30: 138-146.

Murrell JC, Mitchinson SL, Waters D, Johnson CB (2007) Comparative effect of thermal, mechanical, and electrical noxious stimuli on the electroencephalogram of the rat. Bri J Anaesth 98: 366-371.

Murrell JC, White KL, Johnson CB, Taylor PM, Doherty TJ, Waterman Pearson AE (2005) Investigation of the EEG effects of intravenous lidocaine during halothane anaesthesia in ponies. Vet Anaesth Analg 32: 212-221.

Murrell JC, Mitchinson SL, Lesperance L, Sivakumaran S, Johnson CB (2010) Electroencephalography during ovariohysterectomy in rats anaesthetized with halothane. Vet Aanaesth Analg 37: 14-24.

Ong RM, Morris JP, O'dwyer JK, Barnett JL, Hemsworth PH, Clarke IJ (1997) Behavioural and EEG changes in sheep in response to painful acute electrical stimuli. Aust Vet J 75: 189-193.

Otto KA, Voigt S, Piepenbrock S, Deegen E, Short CE (1996) Differences in quantitated electroencephalographic variables during surgical stimulation of horses anesthetized with isoflurane. Vet Surg 25: 249-255.

Schwender D, Daunderer M, Klasing S, Finsterer U, Peter $\mathrm{K}$ (1998) Power spectral analysis of the electroencephalogram during increasing end expiratory concentrations of isoflurane, desflurane and sevoflurane. Anaesthesia 53: 335-342.

Sylvester SP, Johnson CB, Stafford KJ, Ward RN, Mellor DJ (2002) Effects of age on pain sensation following castration in lambs. Paper presented at the Proc N Z Physiol Soc.

Toscani M, Marzi T, Righi S, Viggiano MP, Baldassi S (2010) Alpha waves: a neural signature of visual suppression. Exp Brain Res 207: 213-219.

Trucchi G, Bergamasco L, Argento V (2003) Intraoperative electroencephalographic monitoring: quantitative analysis of bioelectrical data detected during surgical stimulation. Vet Res Commun 27: 803-805.

Woodbury MR, Caulkett NA, Johnson CB, Wilson PR (2005) Comparison of analgesic techniques for antler removal in halothane anaesthetized red deer (Cervus elaphus): cardiovascular and somatic responses. Vet Anaesth Analg 32: 72-82.

Zulkifli I, Goh YM, Norbaiyah B, Sazili AQ, Lotfi M, Soleimani AF, Small AH (2014) Changes in blood parameters and electroencephalogram of cattle as affected by different stunning and slaughter methods in cattle. Anim Prod Sci 54: 187-193. 